\title{
Introduction of Carboxylate Groups at Poly(ethylene) Surfaces by Argon Plasma Immobilization of Sodium Salts of Fatty Acids
}

\author{
J . P. Lens, J . G. A. Terlingen, G. H. M. Engbers, and J . Feijen* \\ Department of Chemical Engineering, Section of Polymer Technology and Biomaterials and \\ Institute for Biomedical Technol ogy (BMTI), University of Twente, P.O. Box 217, \\ 7500 AE Enschede, The Netherlands
}

Received May 5, 1997. In Final Form: September 4, $1997^{\circledR}$

\begin{abstract}
Carboxylate groups were introduced at poly(ethylene) (PE) surfaces by immobilization of sodium 10undecenoate (C11(:)) or sodium dodecanoate (C12) using an argon plasma treatment. The presence of carboxylategroups at thesurfacewas confirmed by ATR-FTIR spectroscopy, contact-angledeterminations, and derivatization XPS. The presence of an unsaturated bond in theal kyl chain of thesurfactant enhanced the immobilization process. About $28 \%$ of the initial amount of carboxylate groups in the precoated C11(:) layer was retained at the PE surface after plasma treatment, as compared to only $6 \%$ for the C12 layer. No changes in the wettability of the modified PE surfaces were observed when they were stored at room temperature for at least 12 weeks. The use of the carboxylate groups that were introduced at polymeric surfaces with this method for further covalent coupling of other molecules is discussed.
\end{abstract}

\section{Introduction}

During the last decades, modification of polymeric surfaces has become an important subject, especially for the improvement of wetting and adhesion. Using appropriate techniques, specific functional groups can be introduced at polymericsurfaces. Thesefunctional groups can then be used for subsequent derivatizations by conventional synthetictechniques. This approach is often applied in biotechnological and biomedical research. Especially the introduction of carboxylic acid and amine groups has been of great interest. ${ }^{1}$ For certain applications, the introduction of specific functional groups at polymeric surfaces is a goal in itself. For example, carboxylateand sulfonategroups wereintroduced at poly(styrene) and poly(urethane) surfaces to improve their bl ood compatibility. ${ }^{2,3}$

With the use of plasma treatment, it is possible to introduce functional groups at the outermost surface of polymericsubstrates.$^{4-7}$ However, oxidativeplasmas give multifunctional surfaces, making it difficult to control the surface chemistry. The use of carbon dioxide plasma treatment has been reported as a way to introduce carboxylic acid groups at polymeric surfaces, but the specificity of this treatment was poor, and several other groups were introduced at the surfaces as well. 8,9

Recently, a new method has been developed to modify polymericsurfaces in a controlled way. ${ }^{10}$ F or this purpose,

\footnotetext{
* Author to whom all correspondence should be addressed.

${ }^{\otimes}$ Abstract published in Advance ACS Abstracts, November 15 , 1997.

(1) Yoshiaki, I. In Functional Monomers and Polymers, Procedures, Synthesis, Applications; Takemoto, K., I naki, Y., Ottenbrite, R. M., Eds.; Marcel Dekker: New York, 1987; Chapter 9.

(2) J ozefonvicz, J .; J ozefowicz, M.J . Biomater. Sci. Polym. Ed. 1990, 1,147 .

(3) Okkema, A. Z.; Cooper, S. L. Biomaterials 1991, 12, 668.

(4) Yasuda, H. J. Makromol. Sci.-Chem. 1976, A10, 383.

(5) Yasuda, H. Plasma Polymerization; Academic: Orlando, FL, 1985. 217.

(6) Coopes, L. H.; Gifkins, K.J . J . Makromol. Sci.-Chem. 1982, A17,

(7) Gerenser, L. J . J . Adhesion Sci. Technol. 1987, 1, 303.

(8) Ko, T.-M.; Lin, J .-C.; Cooper, S. L. J . Colloid InterfaceSci. 1993, 156, 207.

(9) Terlingen, J . G. A.; Gerritsen, H. F. C.; Hoffman, A. S.; Feijen, J. J. Appl. Polym. Sci. 1995, 57, 969.

(10) Terlingen, J . G. A.; Feijen, J .; Hoffman, A. S. J . Biomater. Sci. Polym. Ed. 1992, 4, 31.
}

a compound with a desired functional group, usually a surfactant, is coated onto the surface of a polymeric substrate. Subsequently, the substrate is treated with an argon plasma by which part of the precoated layer is covalently coupled to the surface. With this technique, it was possibletointroducesulfategroups on poly(propylene) (PP) and amine groups on poly(ethylene) (PE) by immobilizing sodium dodecanesulfate(SDS) and decylamine hydrochloride $(\mathrm{DA} \cdot \mathrm{HCl})$, respectively. ${ }^{11,12}$ It was not possibletointroducecarboxylicacid groups at a PE surface by the immobilization of a precoated poly(acrylic acid) (PAAc) layer. This was attributed torapid decarboxylation of PAAc during the argon plasma treatment. ${ }^{13,14}$ Therefore, the requirements for the successful application of this method are that the compound that has to be immobilized can be coated onto the surface and that no severe decomposition of the functional groups takes place during plasma treatment.

The aim of this study is to selectively introduce carboxylate groups at polymeric surfaces. These groups can be used for the coupling of other molecules to the surfaces. In addition, combination of these groups with sulfonate or sulfate groups may improve the blood compatibility of the surface. The introduction of the carboxylate groups should be carried out in a selective way. Furthermore, modifications should be restricted to theoutermost surfacewithout affecting the bulk properties of thematerial. Finally, the method should beapplicable to a wide range of polymeric surfaces. Therefore, the plasma immobilization method seems to be the most suitable approach.

Carboxylate groups are introduced at PE surfaces via the immobilization of the sodium salts of fatty acids. It may be expected that sodium carboxylate groups are less susceptibletoetching during argon plasma treatment than carboxylic acid groups due to hindrance of the dehydrogenation process preceding the decarboxylation. Thus, it

(11) Terlingen, J . G. A.; F eijen, J .; Hoffman, A. S.J . Colloid I nterface Sci. 1993, 155, 55 .

(12) Terlingen, J . G. A.; Brenneisen, L. M.; Super, H. T. J .; Pijpers, A. P.; Hoffman, A. S.; Feijen, J. J . Biomater. Sci. Polym. Ed. 1993, 4, 165.

(13) Terlingen, J. G. A.; Hoffman, A. S.; Feijen, J . J . Appl. Polym. Sci. 1993, 50, 1529.

(14) Terlingen, J . G. A.; Takens, G. A. J .; Gaag, F. J . v. d.; Hoffman, A. S.; Feijen, J. J . Appl. Polym. Sci. 1994, 52, 39. 
may be possible to immobilize part of the coated layer without severe etching of thefunctional groups. By using the sodium salts of a saturated as well as an unsaturated fatty acid, theinfluence of a doublebond in the alkyl chain of the precoated compound on theimmobilization process was studied. Different techniques like ATR-FTIR spectroscopy, contact-angle determinations, contact-angle titrations, and (derivatization) XPS were applied to detect carboxylic acid groups at the modified PE surfaces.

It is also inter esting to know how the composition of the surface of modified polymeric samples changes as a function of time. This process mainly determines the maximum storage time for a possible application. This issue was investigated by determining the contact angles of modified surfaces as a function of the storage time at different temperatures.

\section{Experimental Section}

Materials. PE foil without additives (LDPE, Type 2300, thickness $0.2 \mathrm{~mm}$ ) was obtained from DSM (Geleen, The Netherlands). Argon (purity $\geq 99.999 \%$ ) was purchased from Hoekloos (Schiedam, TheN etherlands). Sodium 10-undecenoate (C11(:)) and sodium dodecanoate (C12) were purchased from Sigma Chemical Co. (St. Louis, MO). N,N'-Di-tert-butylcarbodiimide and poly(acrylic acid) (PAAc) were purchased from Aldrich Chemie (Brussels, Belgium). All other chemicals were purchased from Merck (Darmstadt, Germany). All solvents were of analytical grade quality. All chemicals were used as received.

Cleaning of the Glassware. All glassware was cleaned by rinsing 3 times with toluene, 3 times with acetone, 3 times with water, and finally 3 times with acetone and then dried.

Cleaning of the PE Samples. PE samples $(13 \times 25 \mathrm{~mm})$ were ultrasonically cleaned (10 min, 4 times in each liquid) successively in dichloromethane, acetone, and deionized water and then dried at room temperature (RT) in vacuo.

Preparation of the PAAc Samples. A solution of PAAC in methanol $(2 \%(\mathrm{w} / \mathrm{v}))$ was cast into a clean Petri dish. After evaporation of the methanol, the PAAc sample was dried at RT in vacuo.

Preparation of the C11(:) Pellets. C11(:) was wrapped in aluminum foil and pressed between two copper plates with the use of a hydraulic press. Subsequently, a thin layer of the upper side of the resulting pellet was scraped off with a scalpel.

Coating of C11(:) and C12 onto PE. Clean PE samples were placed in test tubes, and aqueous solutions of $\mathrm{C} 11(:)$ or C12 containing 1 vol \% hexanol were added. The concentration of $\mathrm{C} 11(:)$ was $0.30 \mathrm{M}$, and the concentration of $\mathrm{C} 12$ was $0.10 \mathrm{M}$. After $15 \mathrm{~min}$, the solutions were removed from the test tubes and the polymeric samples were dried at RT in vacuo. The resulting samples are coded PE/C11(:) and PE/C12, respectively.

Plasma Treatment of the Polymeric Samples. Plasma treatments were performed in a tubular reactor (length $80 \mathrm{~cm}$, internal diameter $6.5 \mathrm{~cm}$ ) using three capacitively coupled externally placed electrodes. The hot electrode was placed at the center of the reactor, and the cold electrodes were placed at 10-cm distances at both sides of thehot el ectrode. Theel ectrodes wereconnected to a rf (13.56-M Hz) generator through a matching network. The vacuum side of the reactor was connected to a two-stage rotary pump and a turbomolecular pump. The gas flow to the reactor was controlled by mass flow controllers. The PE and precoated PE samples were placed on glass plates that were put in the center of the reactor between the el ectrodes. The reactor was evacuated to a pressure of $1 \times 10^{-5} \mathrm{mbar}$ and flushed 4 times with argon, after which an argon flow of $10 \mathrm{~cm}^{3} / \mathrm{min}$ (STP) was established through the reactor. After $15 \mathrm{~min}$, the samples were treated with a static argon plasma, i.e., with no flow through the reactor during the plasma treatment ( $45 \mathrm{~W}$, 0.07 mbar). After the plasma treatment, the argon flow was established through the reactor again for $2 \mathrm{~min}$. Subsequently, the reactor was brought to atmospheric pressure with argon. The sampl es were removed from the reactor and turned, and the other side of the samples was plasma treated according to the same procedure.
Washing of the Polymeric Samples. Polymeric samples were immersed in an aqueous solution of $0.1 \mathrm{mM} \mathrm{HCl}$ for $1 \mathrm{~h}$ at $\mathrm{RT}$, rinsed twice with an aqueous solution of $0.1 \mathrm{mM} \mathrm{HCl}$, and dried at RT in vacuo.

Reaction of the Surface Carboxylic Acid Groups with Trifluoroethanol (TFE). The surface carboxylic acid groups were reacted with TFE using a method that was described by Chilkoti et al. ${ }^{15}$ and modified for our purposes. ${ }^{13}$ A polymeric samplewas placed on glass beads in a glass vial. Subsequently, TFE $(0.45 \mathrm{~mL})$, pyridine $(0.20 \mathrm{~mL})$, and $\mathrm{N}, \mathrm{N}^{\prime}$-di-tert-butylcarbodiimide $(0.15 \mathrm{~mL})$ wereconsecutively injected under thesample between the glass beads at $15 \mathrm{~min}$-intervals. Thevial was d osed, and the reaction was allowed to proceed for $24 \mathrm{~h}$ at RT. The sample was then loaded for XPS analysis.

X-ray Photoelectron Spectroscopy (XPS). A Kratos XSAM-800 apparatus equipped with a Mg K $\alpha$ X-ray source (15 $\mathrm{kV}, 10 \mathrm{~mA}$ ) was used to analyze the surface composition of the polymeric samples and C11(:) pellets. The analyzer was placed perpendicular to the sample surface. Survey scans $(0-1100 \mathrm{eV})$ and detail scans were recorded at an analyzer pass energy of 40 eV (FWHM Ag 3d $\mathrm{d}^{5 / 2}$ : $1.2 \mathrm{eV}$ ) and an X-ray spot size with a diameter of $3 \mathrm{~mm}$. Survey scans were used to qualitatively determinethe elemental composition of the samples. No charge neutral ization was applied, and thereported values of the binding energies were referenced to the $C$ is peak for aliphatic carbon, which was assigned a value of $284.8 \mathrm{eV} .{ }^{16}$ The relative peak areas for the different el ements were calculated by numerical integration of the detail scans, considering empirically derived sensitivity factors. After normalization, an elemental composition in atomic percentages was obtained. All calculations were performed using the multi user DS 800 software system (Kratos, Manchester, England).

Contact-Angle Determinations. The advancing and receding contact angles were determined using the Wilhelmy plate technique with the aid of an Electrobalance, Model RM-2, Cahn/ Ventron (Paramount, CA). ${ }^{17}$ The interfacial velocity was $4 \mathrm{~mm} /$ min.

Contact-Angle Titrations. The contact angles of the PE and PE/C11(:) samples that were plasma treated with an argon plasma for $5 \mathrm{~s}$ and washed with an aqueous solution of $0.1 \mathrm{mM}$ $\mathrm{HCl}$ were determined using aqueous solutions of different $\mathrm{pH}$ values. The concentration of the buffers that were used was $0.05 \mathrm{M}$ : $\mathrm{pH} 3$, tartaricacid $(\gamma=71.86 \pm 0.05 \mathrm{mN} / \mathrm{m}) ; \mathrm{pH} 5$, acetic acid $(\gamma=71.95 \pm 0.10 \mathrm{mN} / \mathrm{m}) ; \mathrm{pH} 7, \mathrm{~N}$-(2-hydroxyethyl)piperazine-N'-(2-ethanesulfonic acid) (HEPES) $(\gamma=71.75 \pm$ $0.16 \mathrm{mN} / \mathrm{m}) ; \mathrm{pH}$ 9, 2-(N-cyclohexylamino)ethanesulfonic acid (CHES) $(\gamma=69.80 \pm 0.24 \mathrm{mN} / \mathrm{m}) ; \mathrm{pH} 11, \gamma$-aminobutyric acid $(\gamma=71.75 \pm 0.04 \mathrm{mN} / \mathrm{m})$. For solutions of $\mathrm{pH} 1$ and $\mathrm{pH} 13,0.1$ $\mathrm{N} \mathrm{HCl}(\gamma=71.97 \pm 0.14 \mathrm{mN} / \mathrm{m})$ and $0.1 \mathrm{~N} \mathrm{NaOH}(\gamma=71.69 \pm$ $0.02 \mathrm{mN} / \mathrm{m}$ ) were used, respectively. The surface tension of the solutions were determined with the Wilhelmy plate technique using a platinum plate and a processor tensiometer K 12 , Krüss GmbH (Hamburg, Germany). All measurements wereperformed at RT.

Attenuated Total Reflectance-Fourier Transformed Infrared (ATR-FTIR) Spectroscopy. Polymeric samples were pressed firmly to one side of a KRS-5 crystal and put in a steel sample holder. Absorption spectra were measured with a Biorad FTS- 60 spectrometer (angle 45 $5^{\circ}, 256$ scans, resolution 16 $\mathrm{cm}^{-1}$ ).

Ion Exchange with Plasma-Treated and Washed PE and PE/C 11(:) Samples. PE/C11(:) samples that weretreated with an argon plasma for $5 \mathrm{~s}$ and washed with an aqueous solution of $0.1 \mathrm{mM} \mathrm{HCl}$ wereimmersed in an aqueous $1.0 \mathrm{M} \mathrm{NaOH}$ solution for $60 \mathrm{~min}$ at RT. The $\mathrm{NaOH}$ solution was removed, and the samples were rinsed twice with methanol in order to remove the residual $\mathrm{NaOH} .{ }^{13}$ Finally, thesamples weredried at $\mathrm{RT}$ in vacuo.

Aging of Plasma-Treated and Washed PE and PE/C11(:) Samples. PE and PE/C11(:) samples that weretreated with an argon plasma for $5 \mathrm{~s}$ and washed with an aqueous solution of 0.1 $\mathrm{mM} \mathrm{HCl}$ were stored in clean glass vials for different time

(15) Chilkoti, A.; Ratner, B. D.; Briggs, D. Chem. Mater. 1991, 3, 51.

(16) Wagner, C. D. In Practical Surface Analysis. Volume 1: Auger and X-ray Photoelectron Spectroscopy; Briggs, D., Seah, M. P., Eds.; J ohn Wiley \& Sons: New York, 1990; p 595.

(17) Damme van, H.; Hogt, A. H.; Feijen, J . J . Colloid I nterface Sci. 1990, 114, 167. 
Table 1. XPS Analysis of PE, PE/C11(:), and PE/C12 Samples $(n \geq 4, \pm s d)$

\begin{tabular}{lrl}
\hline \multicolumn{1}{c}{ sample } & atomic $\% \mathrm{O}$ & atomic \% Na \\
\hline $\mathrm{PE}$ & $0.2 \pm 0.3$ & $\mathrm{a}$ \\
$\mathrm{PE} / \mathrm{C} 11(:)$ & $10.9 \pm 1.3$ & $6.2 \pm 0.4$ \\
$\mathrm{PE} / \mathrm{C} 11(:)$, washed & $0.1 \pm 0.2$ & $\mathrm{a}$ \\
$\mathrm{PE} / \mathrm{C} 12$ & $8.3 \pm 2.3$ & $5.0 \pm 0.9$ \\
$\mathrm{PE} / \mathrm{C} 12$, washed & $0.1 \pm 0.1$ & $\mathrm{a}$
\end{tabular}

a Nopeaks were observed in the detail scans of the $\mathrm{Na}$ 1s (10601080-eV) region.

intervalsat $-20,25$, and $50^{\circ} \mathrm{C}$. Theextent of aging of thesamples was evaluated by determining the contact angles of the samples using aqueous $0.1 \mathrm{M} \mathrm{NaOH}$ and $0.1 \mathrm{M} \mathrm{HCl}$ solutions.

\section{Results and Discussion}

Coating of C11(:) and C12 onto PE. XPS analysis of PE samples that had been immersed in an aqueous solution of C11(:) or C12 containing 1 vol \%hexanol showed the presence of substantial amounts of oxygen and sodium at thesurface(Table1). This dearly indicates thepresence of surfactant at the PE surface. The presence of hexanol in the surfactant solution was essential to coat surfactant onto the PE samples.18 From the XPS data, the thicknesses of the coated C11(:) and C12 layers could be calculated. In these calculations, it was assumed that C11(:) and C12 were present in an homogeneous layer on the surface without specific orientation of the surfactant molecules. ${ }^{18}$ The calculated thicknesses were $4.7 \pm 1.2$ and $3.1 \pm 1.5 \mathrm{~nm}$ for the PE/C11(:) and PE/C12 samples, respectively. When the PE/C11(:) and PE/C12 samples werewashed and analyzed with XPS, nosodium or oxygen could be detected at the surface anymore. Thus, all the coated material was removed upon washing.

ThePE/C11(:) and PE/C12 samples weresubsequently treated with an argon plasma for different time intervals to immobilize the surfactants covalently to the surface, after which the samples were washed to remove any unbound material. Surfaceanalyses of thesesamples were performed and are discussed in the following sections.

ATR-FTIR Spectroscopy of (Modified) PE and PE/ C11(:) Samples. ATR-FTIR spectroscopy was performed to gain information about the chemical compositions of modified polymeric samples (Figure 1 ). Differences between the spectra of the modified samples were only observed in the region between 1000 and $2000 \mathrm{~cm}^{-1}$. The predominant peaks for $\mathrm{PE}$, which are characteristic for al kanes, were observed in all spectra: $v_{\text {as }}\left(\mathrm{CH}_{2}\right)$ at 2919 $\mathrm{cm}^{-1}, v_{\text {sy }}\left(\mathrm{CH}_{2}\right)$ at $2844 \mathrm{~cm}^{-1}, \delta_{\mathrm{s}}\left(\mathrm{CH}_{2}\right)$ at $1470 \mathrm{~cm}^{-1}$, and $\delta_{\mathrm{r}}\left(\mathrm{CH}_{2}\right)$ at $720 \mathrm{~cm}^{-1}$. The small peak at $1371 \mathrm{~cm}^{-1} \mathrm{can}$ be ascribed to $\delta_{\mathrm{s}}\left(\mathrm{CH}_{3}\right)$. Plasma treatment induced small differences in the spectrum. Someadditional peaks were detected in the region of $1500-1800 \mathrm{~cm}^{-1}$ and, although very broad, in the region between 1000 and $1300 \mathrm{~cm}^{-1}$. The peaks between 1500 and $1800 \mathrm{~cm}^{-1}$ can be ascribed to oxygen-containing groups like ketones, aldehydes, esters, and carboxylicacid groups $(v(\mathrm{C}=\mathrm{O})$ at $1680-1720$ $\mathrm{cm}^{-1}$ ). The peaks in the region of $1000-1300 \mathrm{~cm}^{-1}$ can be ascribed toalcohols, peroxides, or ethers $(v(\mathrm{C}-\mathrm{O})$ at 1260 1350 and $1000-1250 \mathrm{~cm}^{-1}$ ). Thesefindings indicate that oxygen-containing groups areintroduced on PE during or after the plasma treatment. After washing the plasmatreated PE samples with an aqueous solution of $0.1 \mathrm{mM}$ $\mathrm{HCl}$, no significant changes in the ATR-FTIR spectrum could be observed.

The spectrum of PE/C11(:) is almost identical to the spectrum of PE. Additional to the characteristic peaks

(18) Lens, J . P.; Terlingen, J . G. A.; Engbers, G. H. M.; Feijen, J . Langmuir, submitted.
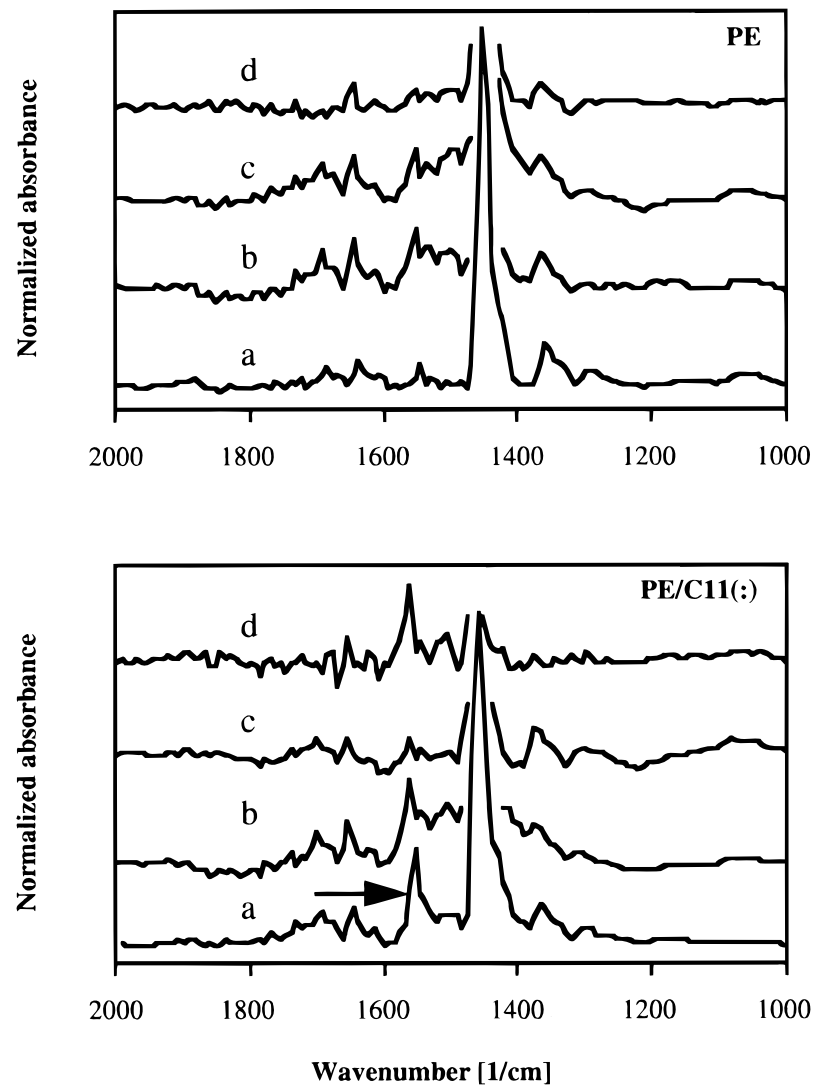

Figure 1. ATR-FTIR spectra of PE and PE/C11(:) samples (a) The samples were treated with an argon plasma for $5 \mathrm{~s}$ (b) and subsequently washed with an aqueous solution of $0.1 \mathrm{mM}$ $\mathrm{HCl}$ (c). Finally, the samples were washed with an aqueous $\mathrm{NaOH}$ solution and methanol (d).

for alkanes, a peak at $1557 \mathrm{~cm}^{-1}\left(v_{\text {as }}\left(\mathrm{COO}^{-}\right)\right)$was detected. This peak arises from the presence of a coated layer of C11(:) on the PE sample. After plasma treatment, the peak arising from the carboxylate group at $1557 \mathrm{~cm}^{-1}$ remains present. After washing with an aqueous solution of $0.1 \mathrm{mM} \mathrm{HCl}$, the carboxylate peak is completely vanished. This may indicate that the coated C11(:) layer was not immobi lized during argon plasma treatment and was washed from the surface. On the other hand, it is also possible that immobilization of C11(:) did take place and that ion exchangehad occurred during the wash step. In this case, the sodium ions are exchanged for protons and car boxylategroups aretransformed to carboxylic acid groups. However, no increased absorption at 1700-1720 $\mathrm{cm}^{-1}$ resulting from $\mathrm{C}=0$ stretching vibrations of the carboxylic acid groups can be observed. Probably, the intensity of these vibrations is too low. To elucidate this uncertainty, spectra of plasma-treated and washed PE and PE/C11(:) samples that wereimmersed in an aqueous $\mathrm{NaOH}$ solution toexchangeacidic protons for sodium ions were recorded. The samples were rinsed with methanol to remove residual $\mathrm{NaOH}$. For the plasma-treated, washed, and ion-exchanged PE/C11(:) samples, the peak at $1557 \mathrm{~cm}^{-1}$ was present again, whereas this peak remained absent for the plasma-treated, washed, and ionexchanged PE samples, indicating the presence of carboxylate groups at the former surfaces. Thus, the immobilization of C11(:) molecules on PE was successful, and the resulting carboxylategroups areavailablefor ion exchange.

However, from this ATR-FTIR study, only limited information was obtained about the characteristics of the outermost surface of the plasma-treated PE and PE/C11(:) samples. This is caused by thelargepenetration depth 

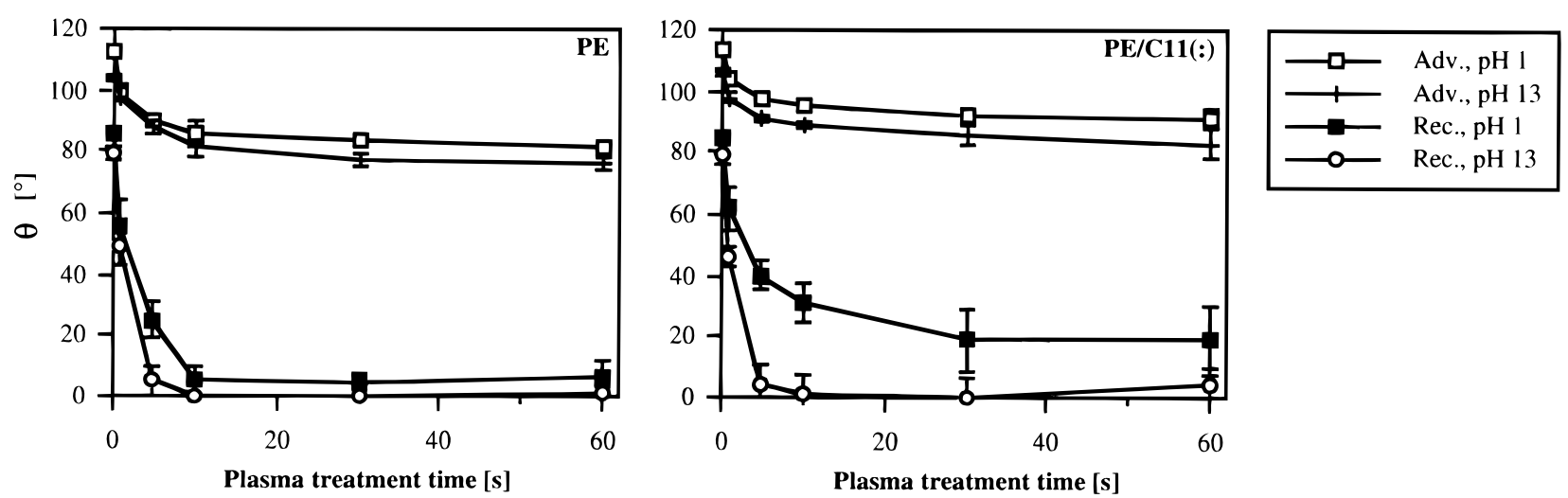

Figure 2. Wilhelmy plate contact-angles of PE and PE/C11(:) samples that were treated with an argon plasma and subsequently washed with an aqueous solution of $0.1 \mathrm{mM} \mathrm{HCl}$. The advancing and receding contact angles are determined using aqueous solutions of $0.1 \mathrm{M} \mathrm{HCl}$ and $0.1 \mathrm{M} \mathrm{NaOH}$ and are given as a function of the plasma treatment time $(\mathrm{n} \geq 6, \pm \mathrm{sd})$.
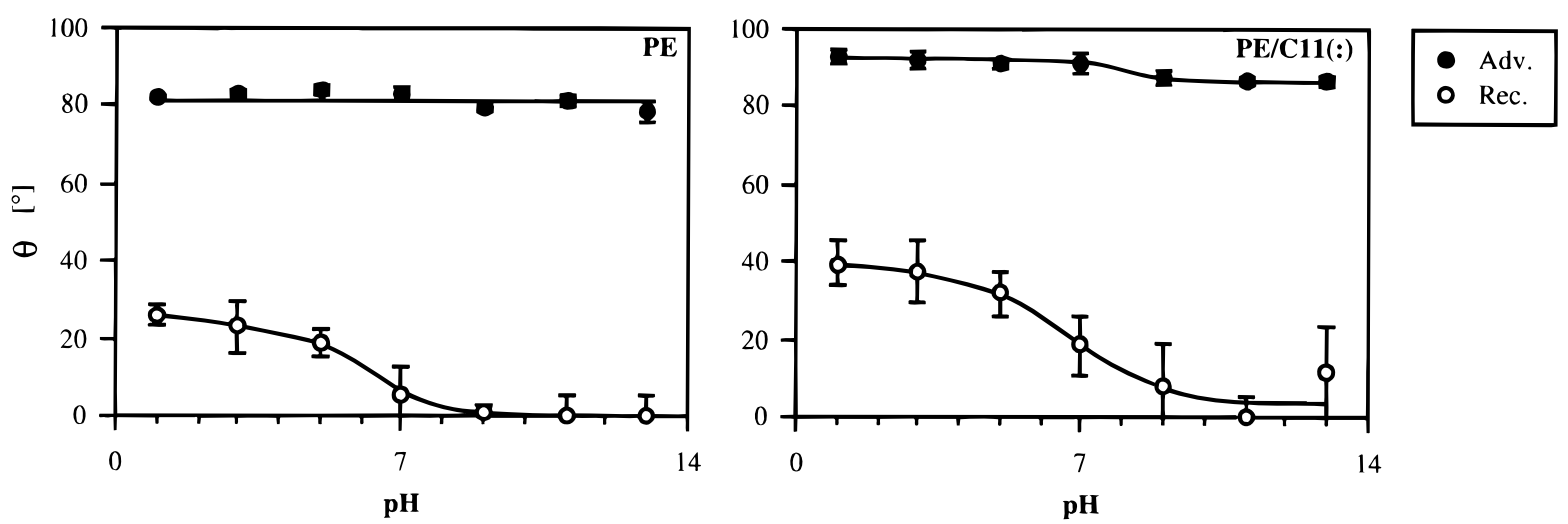

Figure 3. Wilhelmy plate contact-angles of $P E$ and $P E / C 11(:)$ samples that were treated with an argon plasma for $5 \mathrm{~s}$ and subsequently washed with an aqueous solution of $0.1 \mathrm{mM} \mathrm{HCl}$. The advancing and receding contact angles are given as a function of the $\mathrm{pH}$ of the used solution ( $\mathrm{n}=5, \pm \mathrm{sd})$.

of this technique relative to the modified region of the polymericsamples. For the system used, the penetration depth is calculated to be between 500 and $5000 \mathrm{~nm},{ }^{19}$ whereas themodification depth is expected to beonly about $5 \mathrm{~nm}$. Therefore, moresurface-sensitivetechniques have been used to study the surfaces in more detail.

Contact-Angle Determinations of (Modified) PE and PE/C11(:) Samples. The wettability of plasmatreated and washed PE and PE/C11(:) samples was investigated by determining the dynamic contact angles using aqueous solutions of $0.1 \mathrm{M} \mathrm{HCl}$ and $0.1 \mathrm{M} \mathrm{NaOH}$ (Figure2). Theadvancing and thereceding contact angles of plasma-treated and washed PE samples decreased as a function of the plasma treatment time. The advancing contact angle reached a plateau value of $80^{\circ}$ and the receding contact angle reached a constant value of $0^{\circ}$ after a plasma treatment time of $10 \mathrm{~s}$. The decrease in the contact angle is probably due to oxidation of the PE samples during or after the plasma treatment.

The difference between the advancing and receding contact angles is defined as the contact-angle hysteresis. It is indicative of a rough or chemically heterogeneous surface comprising regions of varying wettability ${ }^{20,21}$ but can also be caused by rotational movement of hydrophilic groups away from the polymer/air interface.22 The relatively low contact-angle hysteresis of unmodified PE is due to the surface roughness. Since scanning electron microscopy did not show significant differences between the surface roughness of plasma-treated PE samples and untreated samples, an increased surface roughness is not the reason for the large increase in the contact-angle hysteresis. Most likely, the increase is caused by a combination of the presence of polar groups at thesurface, hydration of the surface, and their reorientation after contact with the liquid phase.

The results of the contact-angle determinations of plasma-treated and washed PE/C11(:) samples differed from that of the PE samples. Again the contact angles decreased as a function of the plasma treatment time. A small difference was observed between the advancing contact angles determined using $0.1 \mathrm{M} \mathrm{HCl}$ and $0.1 \mathrm{M}$ $\mathrm{NaOH}$. After a plasma treatment time of $10 \mathrm{~s}$, the advancing contact angle of plasma-treated and washed PE/C11(:) samples reached a plateau value of $90^{\circ}$. The receding contact angles using $0.1 \mathrm{M} \mathrm{HCl}$ and $0.1 \mathrm{M} \mathrm{NaOH}$ differed strongly from each other, especially for plasma treatment times between 5 and $30 \mathrm{~s}$. This difference was most pronounced at a plasma treatment timeof $5 \mathrm{~s}$. These observations can beascribed to the presence of carboxylic acid groups at the surface of the plasma-treated and washed PE/C11(:) samples. ${ }^{23-27}$

The dynamic contact angles of the PE and PE/C11(:) samples, which were plasma treated for $5 \mathrm{~s}$ and washed,

(19) Couzis, A.; Gulari, E. Langmuir 1993, 9, 3414.
(20) Schwartz, L. W.; Garoff, S. J . Colloid I nterface Sci. 1985, 106, 422.

(21) Li, D.; Neumann, A. W. Colloid Polym. Sci. 1992, 270, 498.

(22) Good, R. J . In Contact Angle, Wettability and Adhesion; Mittal, K. L., Ed.; VSP: Utrecht, The Netherlands, 1993; p 3.

(23) Holmes-Farley, S. R.; Whitesides, G. M. Langmuir 1987, 3, 62.

(24) Holmes-Farley, S. R.; Bain, C. D.; Whitesides, G. M. Langmuir 1988, 4, 920.

(25) Ferguson, G. S.; Chaudhury, M. K.; Biebuyck, H. A.; Whitesides, G. M. Macromolecules 1993, 26, 5870.

(26) Binks, B. P.; Fletcher, P. D. I.; Price, A. Thin Solid Films 1992, 207, 273.

(27) Wang, J .; Frostman, L. M.; Ward, M. D. J . Phys. Chem. 1992 96, 5224. 

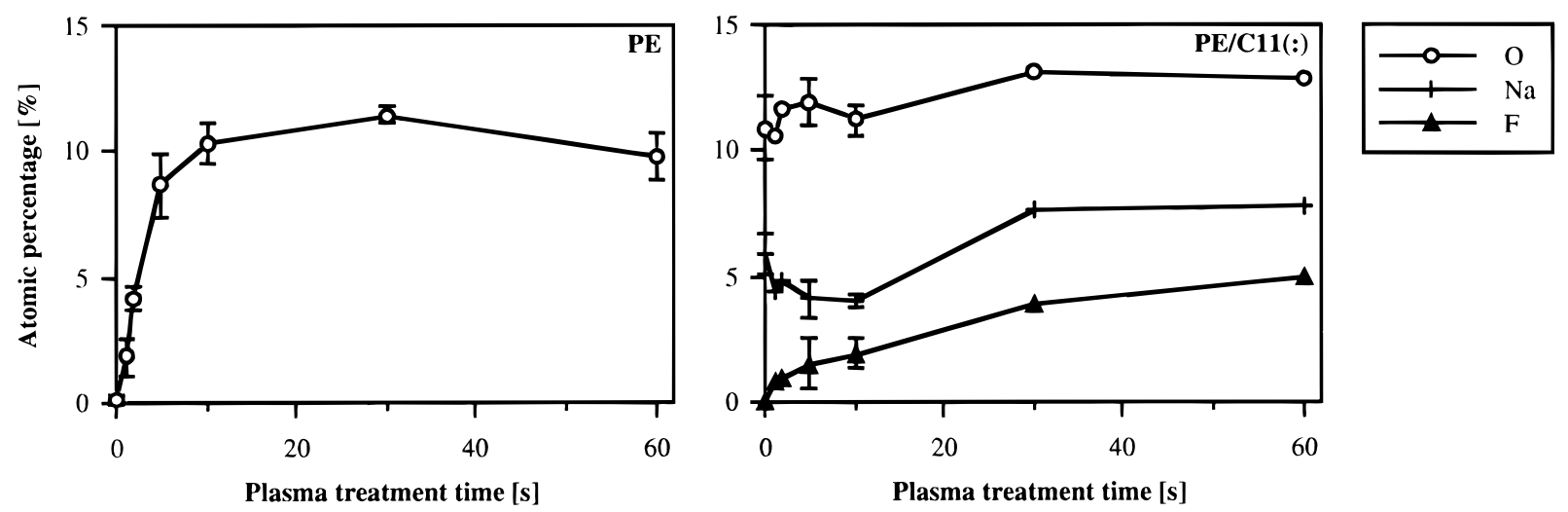

Figure 4. XPS analysis of PE and PE/C11(:) samples that were treated with an argon plasma. The samples were not washed prior toXPS analysis. The atomi c percentages of oxygen, sodium, and fluorineare given as a function of the plasma treatment time (when error bars are shown, $\mathrm{n} \geq 3$ ).

werealso determined using buffer solutions with varying $\mathrm{pH}$ values (Figure 3). It was assumed that, except for proton exchange, possible interactions of buffer constituents with the polymeric surfaces did not influence the contact-angledeterminations. For the plasma-treated and washed PE samples, no significant differences in the advancing contact anglewereobserved over themeasured $\mathrm{pH}$ range. The receding contact angles determined using buffer sol utions with a high $\mathrm{pH}$ werelower than thecontact angles determined at a low $\mathrm{pH}$. The transition was observed at a pH of about 7. Thesametrend was observed for both the advancing and the receding contact angles of plasma-treated and washed PE/C11(:) samples. Although this effect is more pronounced for the receding contact angles than for the advancing contact angles, the advancing contact angles were significantly lower at $\mathrm{pH}=11$ and 13 than at $\mathrm{pH}=1,3$, and $5(\mathrm{p}<0.05)$.

Theobserved dependence of thewettability of polymeric samples on the $\mathrm{pH}$ is due to the presence of ionizable carboxylic acid groups at the surface. At a low pH, carboxylic acid groups present at the surface are protonated. U pon increasing the $\mathrm{pH}$ of the buffer solution, the carboxylic acid groups become more ionized. Due to the presence of the more hydrophilic anions at the surface, the wettability of the polymeric samples increases, resulting in a lower contact angle. At a certain $\mathrm{pH}$, all carboxylic acid groups will be ionized and the contact angle becomes independent of the $\mathrm{pH}$. The $\mathrm{pK}_{\text {surface, }}$ defined as the $\mathrm{pH}$ at which the transition between the higher and lower plateau values of the contact angles is observed, is approximately 7 . This value is shifted about $2-3$ units relative to the $\mathrm{pK}_{\mathrm{a}}$ values of aliphatic carboxylic acids in aqueous solutions. This was also reported for other surfaces containing carboxylic acid groups and was attributed to the difficulty of forming charged groups at the interface. ${ }^{23-28}$ Analogous trends have also been reported for surfaces that contain basic moieties. ${ }^{24,29,30}$

For the plasma-treated and washed PE samples, the effects of varying the $\mathrm{pH}$ of the buffer solution were less pronounced than for the plasma-treated and washed PE/ C11(:) samples. This is probably due to the low amount of carboxylic acid groups on the plasma-treated and washed PE samples compared to the amount on the plasma-treated and washed PE/C11(:) samples.

(28) Cheng, S. S.; Scherson, D. A.; Sukenik, C. N. Langmuir 1995, $11,1190$.

(29) Holmes-Farley, S. R.; Reamy, R. H.; Nuzzo, R.; McCarthy, T.J .; Whitesides, G. M. Langmuir 1987, 3, 799.

(30) Lee, T. R.; Carey, I.; Biebuyck, H. A.; Whitesides, G. M. Langmuir 1994, 10, 741.
XPS Analysis of (Modified) PE , PE/C11(:), and PE/ C12 Samples. Although the presence of carboxylic acid groups at plasma-treated and washed PE/C11(:) samples was demonstrated with the use of ATR-FTIR spectroscopy and contact-angle determinations, these methods yield only qualitative information. Therefore, the modified surfaces wereanalyzed with XPS. Thistechniqueprovides (semi)quantitative information on the chemical composition of the upper $100 \AA$ of the surface. The oxygen level of plasma-treated PE samples increased with increasing plasma treatment time and reached a plateau value of about 11 atom \%at a plasma treatment time of 10 s (F igure 4). This confirms the assumptions made in the previous sections that oxygen-containing groups were introduced at the plasma-treated PE surfaces.

The introduction of oxygen ontoa PE surface by means of an argon plasma treatment is due to the effects of ultraviolet (UV) radiation and chemically active species produced by the plasma. UV radiation as well as the collision of metastables, and possibly ions, with thesurface can producefreeradicals. ${ }^{31}$ Some of theseradicals remain entrapped in the sample and can react with oxygen when the plasma-treated surfaces areexposed toair.32 Besides radical formation, direct surface oxidation is possible if an oxygen source is present during plasma treatment. ${ }^{33}$ Despitethefact that precautions aretaken, oxygen sources such as small air leakages or water adsorbed onto the inside of thereactor walls and possibly onto the polymeric samples are present. Because the surface is also bombarded with argon ions, sputtering (etching) of the polymeric surface takes place. ${ }^{34}$ At prolonged plasma treatment times, the processes of the formation of radicals and oxygen-containing groups at the surface and etching of the surface are in equilibrium. This leads to a constant oxygen level at plasma treatment times of more than $10 \mathrm{~s}$.

The oxygen level of plasma-treated PE/C11(:) samples did not significantly change as a function of the plasma treatment time. Although oxygen is incorporated at the surface of these samples by the same mechanisms as described for the PE samples, carboxylate groups of the coated C11(:) molecules aresimultaneously etched off from

(31) Hudis, M. In Techniques and applications of plasma chemistry; Hollahan, J . R., Bell, A. T., Eds.; J ohn Wiley \& Sons: New York, 1974; Chapter 3.

(32) Shi, M. K.; Christoud, J .; Holl, Y.; Clouet, F. J . M. S.-PureAppl. Chem. 1993, A30, 219.

(33) Clark, D. T.; Dilks, A. J . Polym. Sci., Polym. Chem. Ed. 1977, $15,2321$.

(34) J oubert, O.; Paniez, P.; Pons, M.; Pelletier, J . J . Appl. Phys. 1991, 70, 977. 
Table 2. XPS Analysis of Sodium 10-Undecenoate (C11(:)) before and after Treatment with an Argon Plasma for $150 \mathrm{~s}$

\begin{tabular}{clllll}
\hline & \multicolumn{5}{c}{ atomic \% } \\
\cline { 2 - 6 } compd & \multicolumn{1}{c}{$\mathrm{C}$} & \multicolumn{1}{c}{$\mathrm{O}$} & $\mathrm{Na}$ & $\mathrm{F}$ & $\mathrm{Si}$ \\
\hline $\mathrm{C} 11(:)$ & $76.7(78.6)$ & $14.3(14.3)$ & $9.0(7.1)$ & $\mathrm{b}$ & $\mathrm{b}$ \\
$\begin{array}{c}\text { C11(:), stored in } \\
\text { plasma reactor }\end{array}$ & 76.3 & 13.1 & 9.7 & 0.9 & $\mathrm{~b}$ \\
$\begin{array}{c}\text { C11(:), Ar 150 s, } \\
\quad \text { Ar reactor }\end{array}$ & 61.4 & 17.1 & 16.7 & 4.8 & $\mathrm{~b}$ \\
$\begin{array}{c}\text { C11(:), Ar 150 s, } \\
\text { CF }\end{array}$ & 48.3 & 18.9 & 14.8 & 16.6 & 1.4 \\
& & & & &
\end{tabular}

a The theoretical values for the untreated materials are given in parentheses. The C11(:) pellets were either stored in the plasma reactor for $14 \mathrm{~h}$, treated with an argon plasma, or treated with an argon plasma in a reactor that is normally used for $\mathrm{CF}_{4}$ plasma treatments. ${ }^{b}$ No peaks were observed in the detail scans of the $F$ Is $(680-700-\mathrm{eV})$ or $\mathrm{Si} 2 \mathrm{p}(95-115-\mathrm{eV})$ region.

the surface (decarboxylation). Incorporation of oxygen at thesurfaceand decarboxylation result in a constant oxygen level of the plasma-treated PE/C11(:) samples at plasma treatment times longer than $2 \mathrm{~s}$.

Besides the expected elements such as oxygen and sodium, also fluorine was detected at the surface of the plasma-treated PE/C11(:) samples. This fluorine level increased with increasing plasma treatment time. The binding energy of the $F$ is electrons was $684.5 \pm 0.3 \mathrm{eV}$, suggesting the presence of fluorineas fluorideions ${ }^{35}$ Since no el ements other than carbon, oxygen, and sodium were detected at the surface, it seems likely that the fluorine is present in $\mathrm{NaF}$. The reported binding energy of $\mathrm{F}$ 1s electrons in $\mathrm{NaF}$ is $684.5 \mathrm{eV}$. ${ }^{36}$ With conventional titration techniques, no fluoride ions could be detected in C11(:). Therefore, it can be concluded that the fluorine contamination was not present in the surfactant but was introduced during the argon plasma treatment.

To study the effects of an argon plasma treatment on C11(:), pellets of this surfactant wereprepared and treated with an argon plasma for $150 \mathrm{~s}$. Both untreated and plasma-treated pel lets wereanalyzed with XPS (Table2). The theoretical and measured el emental compositions of the untreated material agreed well. A small amount of fluorine was detected on the untreated pellet which was stored in the gas plasma reactor at a pressure of $10^{-6}$ mbar for $14 \mathrm{~h}$. After argon plasma treatment, the atomic percentage of oxygen and sodium detected on the pellet was increased. Theshoulder at thehigher binding energy side of the $C$ is spectra of the original pellets was largely reduced for the plasma-treated materials, indicating a strong decarboxylation of the materials (spectra not shown). Furthermore, an increase in the atomic percentage of fluorine was detected. The binding energy of the $\mathrm{F}$ 1s peak for all pellets was $684.7 \pm 0.7 \mathrm{eV}$. This also indicates that the fluorine introduced during the argon plasma treatment was probably present in the form of $\mathrm{NaF}$.

Theintroduction of fluorineonto thePE/C11(:) samples and thesurfactant pellets during argon plasma treatment can be explained by the fact that the plasma apparatus is al so used for tetrafluoromethane $\left(\mathrm{CF}_{4}\right)$ plasma treatment of polymers. Although the $\mathrm{CF}_{4}$ and argon treatments are performed in different glass reactors, it is possible that fluorine-containing species remain at the walls of parts of the equipment that are not exchanged. During

(35) Briggs, D. In Practical Surface Analysis. Volume 1: Auger and X-ray Photoel ectron Spectroscopy; Briggs, D., Seah, M. P., Eds.; J ohn Wiley \& Sons: New York, 1990; $\mathrm{p} 437$.

(36) Nefedov, V.I.; Salyn, Y. V.J . Electron. Spectrosc. Relat. Phenom. 1977, 10, 121. evacuation and argon plasma treatment, fluoride-containing species can be rel eased from these parts and form $\mathrm{NaF}$ with the positively charged sodium ions on the PE/ C11(:) samples or C11(:) pellets. Toverify this assumption, a C11(:) pellet was treated with an argon plasma for 150 sin theglass reactor normally used for the $\mathrm{CF}_{4}$ treatments. XPS analysis of this pellet showed a very high atomic percentage of fluorine (Table 2). The $\mathrm{F}$ 1s spectrum consisted of two peaks with binding energies of 685.4 and $687.1 \mathrm{eV}$. Additional silicon was detected at the surface $(103.8 \mathrm{eV})$. In this respect, it is worth mentioning that during plasma treatment of $\mathrm{NaCl}$ with fluorine-containing plasmas, $\mathrm{Na}_{2} \mathrm{SiF}_{6}$ was formed through the reaction of sodium ions with a fluorsilicon compound such as $\mathrm{SiF}_{4}$. The binding energies of the $F$ is and Si $2 p$ electrons in $\mathrm{Na}_{2} \mathrm{SiF}_{6}$ are 686.4 and $104.2 \mathrm{eV}$, respectively. The formation of $\mathrm{Na}_{2} \mathrm{SiF}_{6}$ was considered to be a consequence of ablation of silicon from the glass tube. ${ }^{37,38}$ It is very well possible that the formation of $\mathrm{NaF}$ during argon plasma treatment of the PE/C11(:) samples and the introduction of fluorineand silicon at thesurfactant pellets in this study is caused by analogous mechanisms.

In Figure 5, the results of the XPS analysis of plasmatreated samples which were subsequently washed with an aqueous solution of $0.1 \mathrm{mM} \mathrm{HCl}$ are presented. The oxygen levels of the plasma-treated and washed PE samples were comparable to the oxygen levels of the nonwashed PE samples. Theatomic percentage of oxygen on the plasma-treated and washed PE/C11(:) samples was smaller than the atomic percentage detected on the plasma-treated PE/C11(:) samples beforewashing and also smaller than on the plasma-treated PE samples. Apparently, part of theoxygen-containing material is washed off from the plasma-treated PE/C11(:) samples. Oxygen of two different origins is probably removed from the plasma-treated PE/C11(:) samples during the washing procedure: carboxylate groups of surfactant molecules that are not immobilized on the surface and oxygencontaining groups introduced during or after plasma treatment on thesesurfactant molecules. N osodium could be detected on the plasma-treated and washed PE/C11(:) samples. So if C11(:) molecules were immobilized on the surface, the carboxylate groups were protonated during washing with an aqueous solution of $0.1 \mathrm{mM} \mathrm{HCl}$. The possibility of this ion exchangewas al ready demonstrated in the previous sections on ATR - FTIR spectroscopy and contact-angle determinations. After washing of the plasma-treated PE/C11(:) samples, also no fluorine could be detected at these surfaces anymore, indicating that the fluorine-containing contamination could easily be removed.

In order to detect carboxylic acid groups at the surface of plasma-treated and washed PE and PE/C11(:) samples, these samples were subjected to a derivatization reaction with TFE and analyzed with XPS. The results are presented in Figure 6. The oxygen levels of the TFEderivatized samples were the same as the oxygen levels of thesamples beforederivatization. Thefluorinecontent of the PE samples increased with increasing plasma treatment time and reached a plateau value of 1 atom \% at a plasma treatment time of $10 \mathrm{~s}$. The fluorine level of the PE/C11(:) samples initially increased with the plasma treatment time, reached a maximum of 5.3 atom $\%$ at a plasma treatment time of $5 \mathrm{~s}$, and subsequently decreased.

XPS analysis of the TFE-derivatized PAAc samples showed values of 19.5 atom $\% O$ and 29.8 atom $\% \mathrm{~F}$ at the

(37) Denes, F.; Sarmadi, M.; Hop, C. E. C. A.; Buncick, M.; Young R. J . Appl. Polym. Sci. 1994, 52, 1419.

(38) Masuoka, T.; Yasuda, H.J .Polym. Sci., Polym. Chem. Ed. 1982, $20,2633$. 

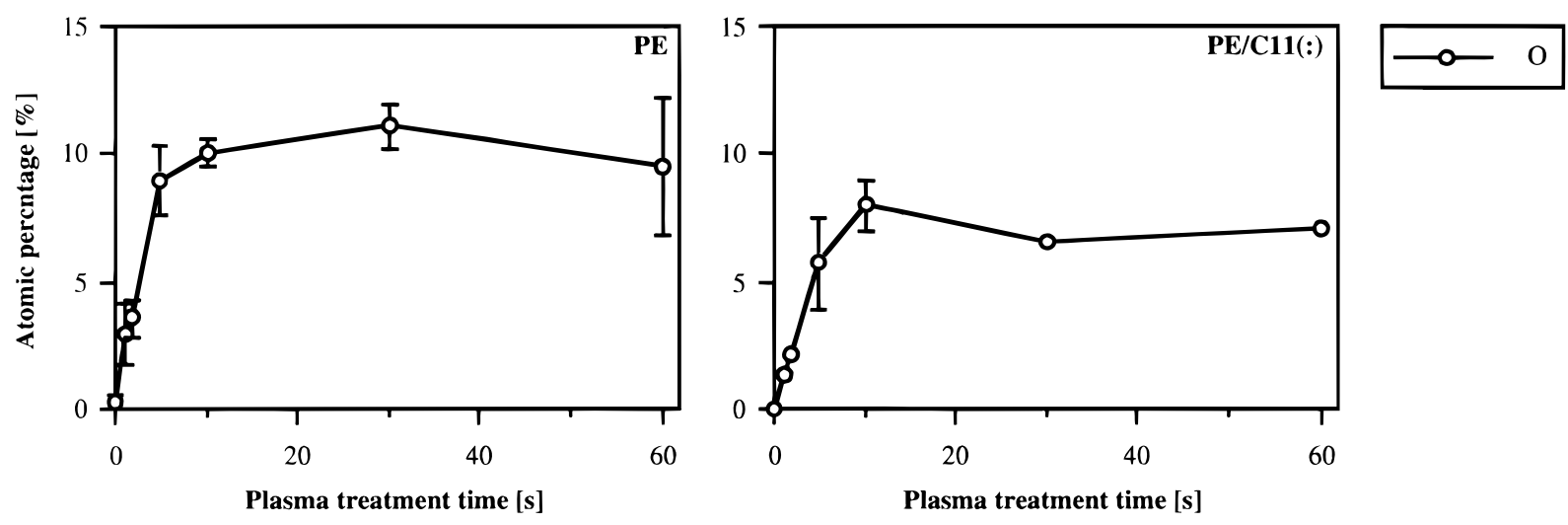

Figure 5. XPS analysis of PE and PE/C11(:) samples that were treated with an argon plasma and subsequently washed with an aqueous solution of $0.1 \mathrm{mM} \mathrm{HCl}$. The atomic percentages of oxygen are given as a function of the plasma treatment time (when error bars are shown, $\mathrm{n} \geq 3$ ).
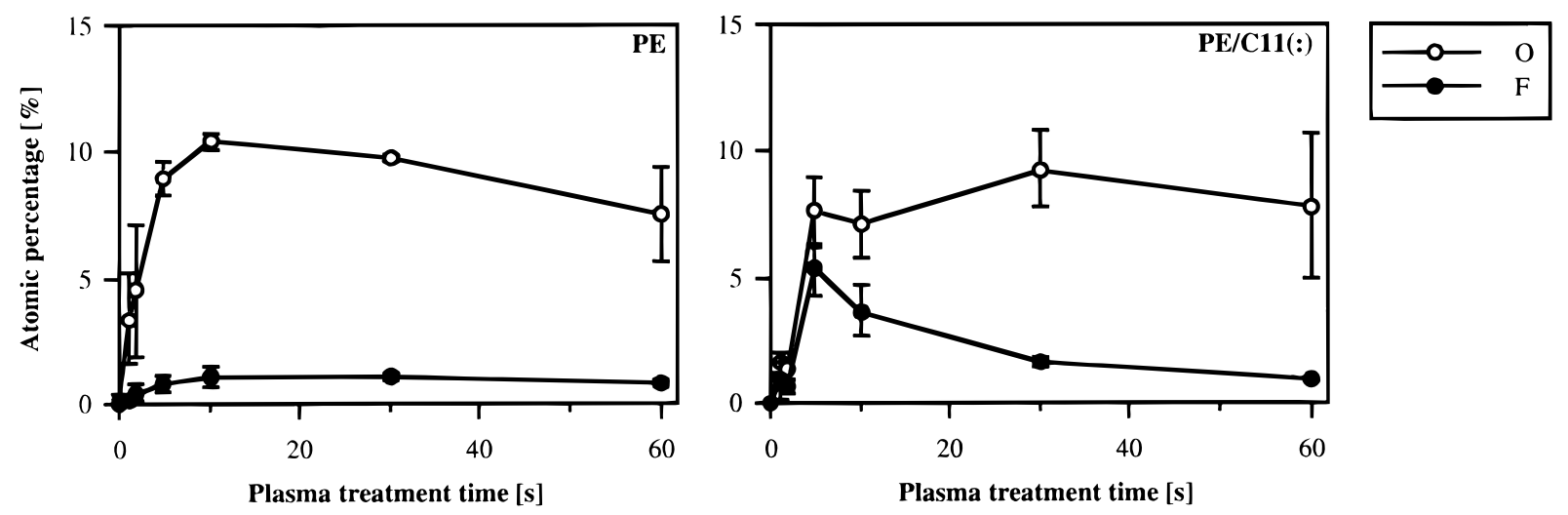

Figure 6. XPS analysis of PE and PE/C11(:) samples that were treated with an argon plasma, washed with an aqueous solution of $0.1 \mathrm{mM} \mathrm{HCl}$, and derivatized with TFE totag carboxylicacid groups at the surface. The atomic percentages of oxygen and fluorine are given as a function of the plasma treatment time (when error bars are shown, $n \geq 3$ ).

surface compared to the expected theoretical values of 20 and 30 atom\% at complete conversion of all thecarboxylic acid groups present in the analyzed surface layer. Thus, TFE almost quantitatively reacts with carboxylic acid groups present at the surface of PAAc samples. Since TFE shows a minor side reaction only with surface epoxides, ${ }^{39}$ the atomic percentage of fluorine is representative for the atomic percentage of oxygen present in carboxylic acid groups esterified with TFE at a surface. Thus, it can be calculated that at a plasma treatment time of $5 \mathrm{~s}, 47 \%$ of the oxygen detected at the surface of the plasma-treated and washed PE/C11(:) samples is present in carboxylic acid groups esterified with TFE compared to $7 \%$ for $\mathrm{PE}$. Consequently, it is possible to introduce a relatively large amount of carboxylic acid groups onto PE by immobilizing a carboxylate-groupcontaining surfactant on a PE surface. Compared to the $\mathrm{CO}_{2}$ plasma treatment of PE where only $14-25 \%$ of the oxygen introduced at the surfacewas present in carboxylic acid groups, 8,9 the selectivity toward the introduction of carboxylic groups at a polymeric surface is greatly enhanced.

The competition between the immobilization and the removal of the coated surfactant layer due to etching of the surface is evident (Figure 6). I mmobilization of C11(:) on PE resulted in theintroduction of carboxylategroups ontothesurface. However, after a plasma treatment time of $10 \mathrm{~s}$, etching played a predominant role, resulting in a decrease in the amount of carboxylate groups. Apparently, the decarboxylation of the C11(:) layer is not as fast

(39) Takens, G. A. J .; Dinteren van, C. P. W.; Terlingen, J . G. A.; Engbers, G. H. M.; Feijen, J. Surf. Interface Anal., submitted.

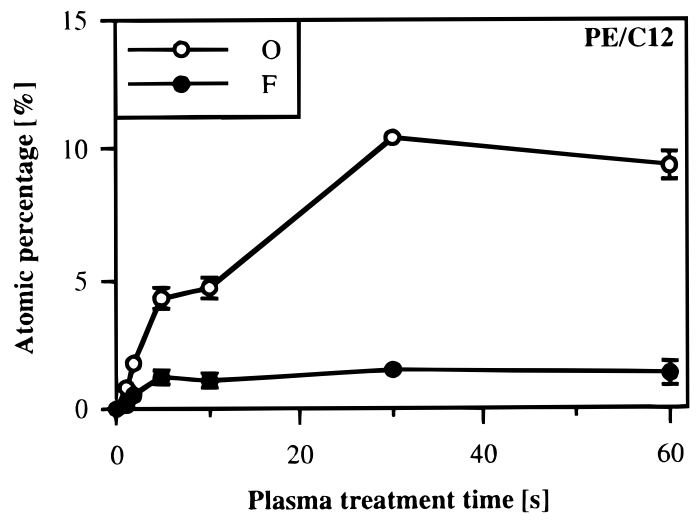

Figure 7. XPS analysis of PE/C12 samples that were treated with an argon plasma, washed with an aqueous solution of 0.1 $\mathrm{mM} \mathrm{HCl}$, and derivatized with TFE totag carboxylicacid groups at the surface. The atomic percentages of oxygen and fluorine are given as a function of the plasma treatment time (when error bars are shown, $n \geq 3$ ).

as found for PAAC, ${ }^{13}$ supporting the hypothesis that the sodium carboxylates aremorestableduring argon plasma treatment than thecarboxylicacid groups. Consequently, it was possible to immobilize part of the coated C11(:) on PE before the surfactant layer was completely decarboxylated.

In Figure7, theXPS results of plasma-treated, washed, and TFE-derivatized PE/C12 samples are presented. Although the atomic percentage of fluorine measured at these surfaces was higher than on the PE samples, it was much lower than theatomic percentage of fluorine detected on the PE/C11(:) samples. Thus, it can be concluded that 

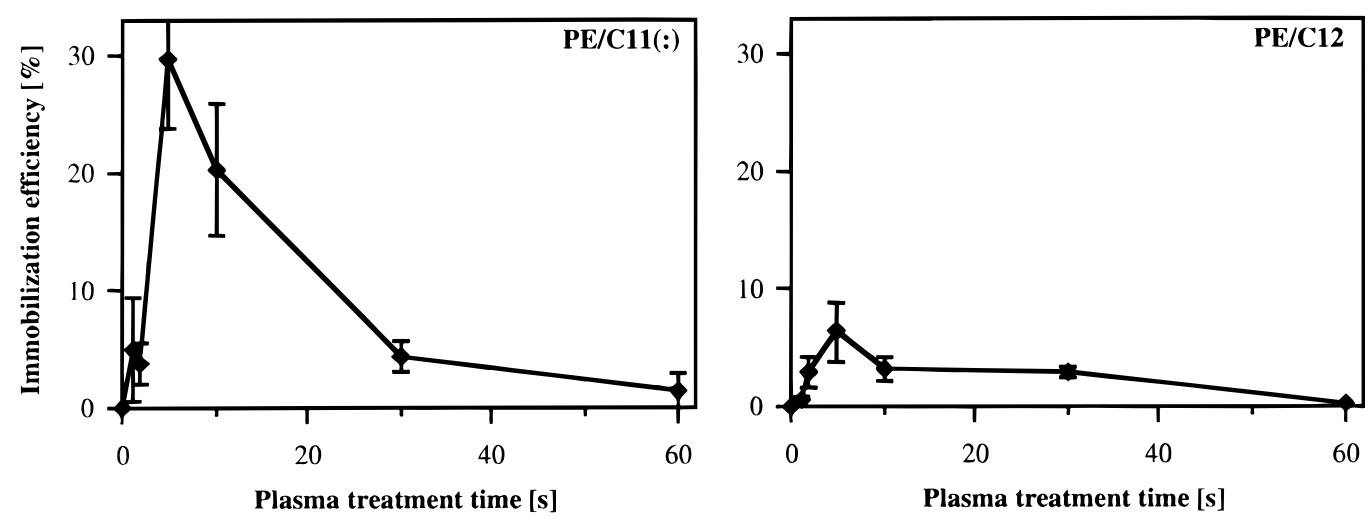

Figure 8. I mmobilization efficiency of a precoated layer of C11(:) and C12 onto PE given as a function of the argon plasma treatment time. The efficiency was calculated according to eq 1 (when error bars are shown, $n \geq 3$ ).

also C12 can be immobilized on PE, although the immobilization is less effective than the immobilization of C11(:) on PE.

Immobilization E fficiencies of C11(:) and C12 on PE. The results of immobilization of C11(:) and C12 on PE can be compared to each other by calculating their immobilization efficiencies (Figure8). Theimmobilization efficiency is defined as the atomic percentage of oxygen present in carboxylicacid groups of immobilized surfactant molecules relative to the atomic percentage of oxygen present in carboxylate groups on precoated polymeric samples. The immobilization efficiency of C11(:) on PE is calculated according to (see Appendix)

immobilization efficiency of $\mathrm{C} 11(:)$ on $\mathrm{PE}[\%]=$

$$
\frac{\left\{\frac{\mathrm{O}_{\mathrm{PE}} \mathrm{F}_{\mathrm{PE} / \mathrm{C} 11(:)}-\mathrm{O}_{\mathrm{PE} / \mathrm{C} 11(\mathrm{:})} \mathrm{F}_{\mathrm{PE}}}{1.5 \mathrm{O}_{\mathrm{PE}}-\mathrm{F}_{\mathrm{PE}}}\right\}_{\mathrm{PE} / \mathrm{C} 11(\mathrm{:}) \text {, coated }}}{\mathrm{O}} 100
$$

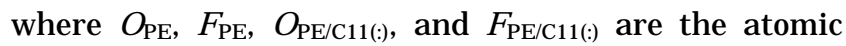
percentages of oxygen and fluorine on plasma-treated, washed, and TFE-derivatized PE and PE/C11(:) samples, respectively, and $\mathrm{O}_{\mathrm{PE} / \mathrm{C} 11(\mathrm{:}) \text {, coated }}$ is the atomic per centage of oxygen on the precoated PE/C11(:) samples. The calculation of the immobilization efficiency of C12 on PE is performed using an equation analogous to eq 1 .

The immobilization efficiency of C11(:) and C12 on PE showed a maximum at a plasma treatment time of $5 \mathrm{~s}$, but the absolute value was much higher for $\mathrm{C} 11($ :) than for C12. At a plasma treatment time of $5 \mathrm{~s}, 28 \%$ of the initial amount of carboxylategroups in the precoated C11(:) layer was retained at the PE surfaces, whereas this was only $6 \%$ in the case of C12. These differences are caused by the presence of the terminal double bond of C11(:). Immobilization of surfactants on polymeric surfaces probably proceeds through a radical mechanism. Radicals are generated at the polymeric surface and the aliphatic chains of the surfactant molecules during plasma treatment. Recombination of a surfaceradical and a surfactant radical leads to the formation of a covalent bond. In addition, a surface radical may open the $\mathrm{C}=\mathrm{C}$ bond of unsaturated surfactants. Apparently, this process has a higher probability than the recombination of a surface radical and a surfactant radical. Thus, unsaturation in the alkyl chain promotes the covalent coupling of $\mathrm{Cl1}(:)$ to the PE surface.

Based upon the thickness of the initially coated surfactant layers and the maximum values of the immobilization efficiency, an estimation can be made of the minimum surface area per carboxylic acid group for the immobilization of C11(:) $\left(\rho=0.99 \mathrm{~g} / \mathrm{cm}^{3} ; \mathrm{M}=206.3 \mathrm{~g} / \mathrm{mol}\right)$ and C12 $\left(\rho=0.99 \mathrm{~g} / \mathrm{cm}^{3} ; M=224.3 \mathrm{~g} / \mathrm{mol}\right)$. This results in values of 27 and $190 \AA^{2}$ for theimmobilization of $C 11(:)$ and $\mathrm{C} 12$ on $\mathrm{PE}$, respectively. Taking into account the geometry of the C11(:) molecules, this would mean that on an average base about a monolayer of $\mathrm{C} 11(\mathrm{:})$ is immobilized on the PE surface. However, such a monolayer is not an accurate picture of the actual situation becausenoordered structure of theimmobilized surfactant molecules is expected after plasma treatment.

The values of the immobilization efficiency obtained in this study aresomewhat in contrast with previous studies on theimmobilization of surfactants on polymericsurfaces by means of an argon plasma treatment. I mmobilization efficiencies of $25 \%$ and $50 \%$ were reported when immobilizing SDS and DA $\cdot \mathrm{HCl}$, both saturated surfactants, on PP and PE, respectively. ${ }^{11,12}$ These differences may be explained by the fact that not only is the aliphatic chain of thesurfactant of importance but thechemical structure of the surface also plays a predominant role (as for SDS on PP). In thecase of theimmobilization of $\mathrm{DA} \cdot \mathrm{HCl}$, other aspects like immobilization through the functional group seem to play a role. A detailed study on the mechanism of immobilization of surfactants onto polymeric surfaces, in which the influence of the doublebond in thesurfactant chain and different polymeric substrates is discussed, is presented elsewhere. 40,41

Aging of the Modified PE Samples. Polymeric surfaces modified by gas plasma treatments may be susceptible to aging. ${ }^{9,42,43}$ This process depends on a number of factors such as temperature and storage environment and is responsible for changes in the surface compositi on of modified polymeric samples upon storage. Functional groups, initially present at the surface, can migrate away from the interface between the polymer and its environment in order to minimi ze the surface free energy. Theserearrangements are initially limited tothe upper layer of the surface and are presumably reversible. At prolonged storage times, segments containing functional groups can migrate further into the bulk of the polymer. This process is diffusion controlled and is claimed to be irreversible. 9,43,44

Thestability of the plasma-treated and washed PE and PE/C11(:) samples was investigated by storing them in

(40) Lens, J . P.; Terlingen, J . G. A.; Engbers, G. H. M.; Feijen, J . J . Polym. Sci., Polym. Chem. Ed., submitted.

(41) Lens, J . P.; Spaay, B.; Terlingen, J . G. A.; Engbers, G. H. M.; Feijen, J.J . Plasmas Polym., submitted.

(42) Ferguson, G. S.; Whitesides, G. M. In Modern Approaches to Wettability. Theory and Appli cations; Schroder, M. E., Loeb, G. L., Eds.; Plenum: New York, 1992; p 143.

(43) Takens, G. A. J .; Dinteren van, C. P. W.; Terlingen, J . G. A.I Engbers, G. H. M.; Feijen, J . Langmuir, submitted.

(44) Holmes-Farley, S. R.; Whitesides, G. M. Am. Chem. Soc., Polym. Mater. Sci. Eng. Prepr. 1985, 53, 127. 

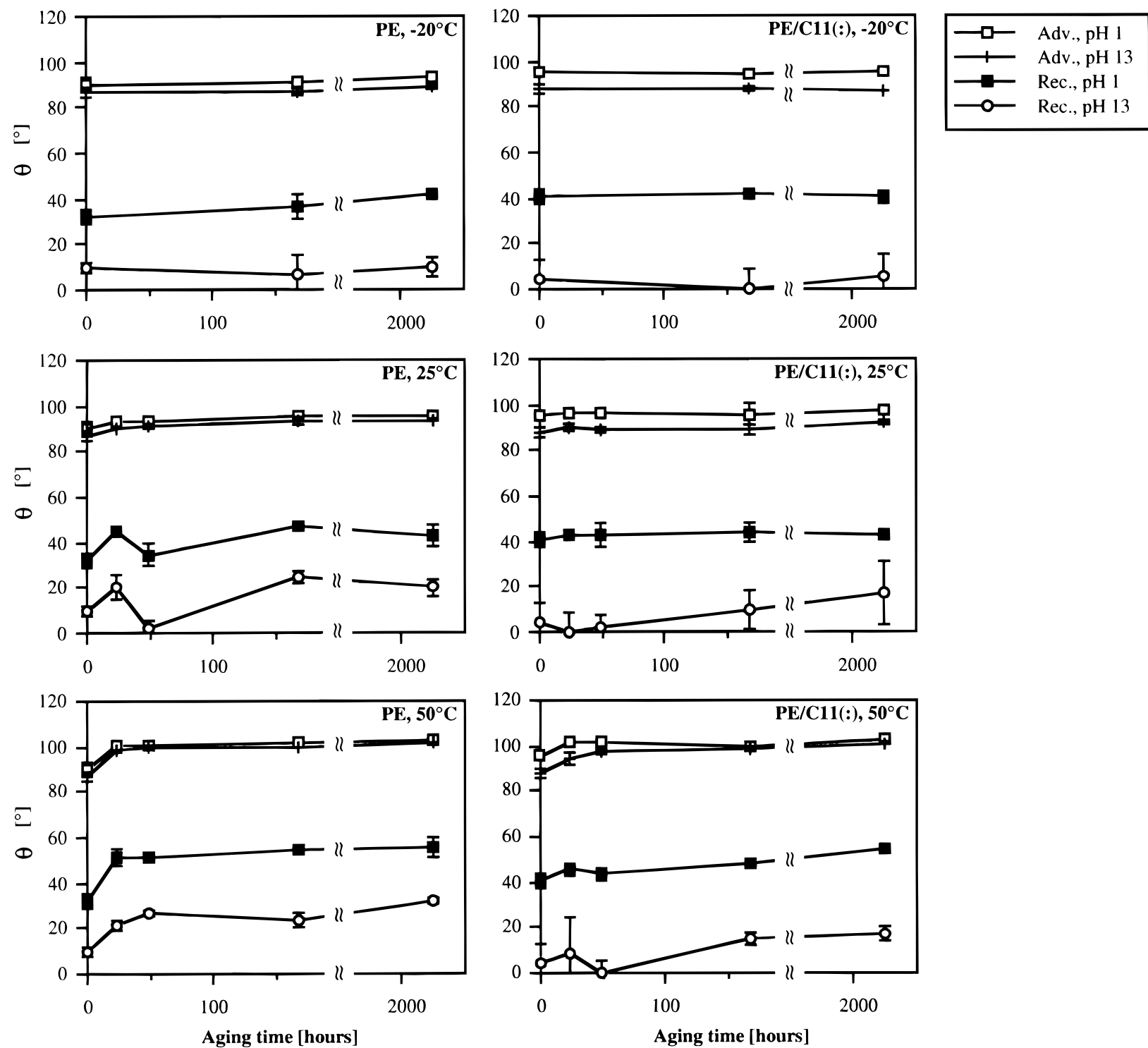

Figure 9. Wilhelmy plate contact-angles of PE and PE/C11(:) samples that were treated with an argon plasma for $5 \mathrm{~s}$ and subsequently washed with an aqueous solution of $0.1 \mathrm{mM} \mathrm{HCl}$. The advancing and receding contact angles are determined using aqueous solutions of $0.1 \mathrm{M} \mathrm{HCl}$ and $0.1 \mathrm{M} \mathrm{NaOH}$ and are given as a function of the storage time at $-20,25$, and $50{ }^{\circ} \mathrm{C}$ in air ( $\mathrm{n}$ $=3, \pm \mathrm{sd})$.

air at $-20,25$, and $50{ }^{\circ} \mathrm{C}$ and by determining their wettability. Therefore, contact-angle determinations using aqueous solutions of $0.1 \mathrm{M} \mathrm{HCl}$ and $0.1 \mathrm{M} \mathrm{NaOH}$ were performed at different timeintervals(Figure9). At storage temperatures of -20 and $25^{\circ} \mathrm{C}$, no significant changes in the contact angles were observed up to an aging time of $2000 \mathrm{~h}$ (12 weeks). At $50^{\circ} \mathrm{C}$, both the plasma-treated and washed PE and PE/C11(:) samples showed a rapid increase in the advancing and receding contact angles within the first 2 days, after which they remained constant. The difference between the contact angles determined using $0.1 \mathrm{M} \mathrm{HCl}$ and $0.1 \mathrm{M} \mathrm{NaOH}$ remained also largely unaffected for the plasma-treated and washed PE and $\mathrm{PE} / \mathrm{C} 11($ : $)$ samples stored at -20 and $25^{\circ} \mathrm{C}$. U pon storage at $50^{\circ} \mathrm{C}$, the difference between thevalues of theadvancing contact angles of the plasma-treated and washed PE/C11(:) samples disappeared. The difference between the values of thereceding contact angles of the plasma-treated and washed PE samples seemed to become smaller, whereas for the values of the receding contact angles of the plasma-treated and washed PE/C11(:) samples, this difference remained the same.
The contact angles remained unchanged upon storage at $-20{ }^{\circ} \mathrm{C}$ because at this temperature the mobility of functional-group-containing polymer chains islow. Upon increasing the temperature, the mobility increases and the contact angles will increase upon storage. At $25^{\circ} \mathrm{C}$, no significant changes could be observed, which indicates that the mobility is still limited. These observations are in contrast to the results of studies on the aging of $\mathrm{CO}_{2}$ plasma-treated PE surfaces. ${ }^{9,43}$ In these studies, a rapid reorganization of the surface was observed when the $\mathrm{CO}_{2}$ plasma-treated polymeric samples were stored in air at room temperature. An explanation for the observed stability of the plasma-treated and washed PE and PE/ C11(:) samples is that argon and other noble gas plasma treatments of polymers result in a highly cross-linked surface matrix. ${ }^{45-47}$ Therefore, thechain segments at the

(45) Hansen, R. H.; Schonhorn, H.J . Polym. Sci., Polym. Lett. 1966, 4, 203.

(46) Schonhorn, H.; Hansen, R. H. J . Appl. Polym. Sci. 1967, 11, 1461. 179. 
surface may have a very restricted mobility, preventing large-scale rearrangements.

The rapid increase in the values of the contact angles in the first 2 days of storage at $50{ }^{\circ} \mathrm{C}$ may be caused by themovements of the pol ymer segments near thesurface. It is possible that carboxylic acid groups at the surfaces of the plasma-treated and washed PE/C11(:) samples migrate away from the polymer-air interface at higher temperatures. Theoccurrence of this process is indicated by the convergence of the values of the advancing contact angles determined using $0.1 \mathrm{M} \mathrm{HCl}$ and $0.1 \mathrm{M} \mathrm{NaOH}$. Becausethedifference between the values of the receding contact angles using these media remained unaltered, it is concluded that the rearrangements are only restricted to the uppermost surface and that the carboxylic acid groups al ready reappear at the polymer-liquid interface within thetimeinterval necessary toperform the contactangle determinations, which is of the order of a few minutes.

Applicability of the Current Modification Method. The method of introducing carboxylic acid groups at PE can probably be expanded to a wide variety of polymeric surfaces, although in each particular case the method should be optimized. Furthermore, the geometries of the polymeric substrates can be varied, which makes this method widely applicable. The carboxylic acid groups introduced with this method areavailablefor ion exchange, as was shown by ATR-FTIR spectroscopy and contactangle determinations. Furthermore, XPS showed that small molecules likeTFE can becovalently coupl ed to the carboxylic acid groups. The carboxylic acid groups are also suitable for reaction with larger molecules carried out in sol ution. In a separate study, it was demonstrated that thecarboxylicacid groups can beused for thecovalent immobilization of large molecules to the surface. Albumin-heparin conjugate was immobilized on PS surfaces via activation of carboxylic acid groups that were introduced at a PS surface by means of the method reported in this paper. ${ }^{48}$

\section{Conclusions}

Carboxylate groups can be introduced at PE surfaces by immobilizing a precoated layer of the sodium salt of a fatty acid. The precoated layer was immobilized on the polymeric surface by means of an argon plasma treatment. The carboxylate groups are available for ion exchange and further coval ent coupling. The presence of a carboncarbon double bond in the alkyl chain of the sodium salt of the fatty acid enhances the immobilization efficiency. The selectivity and yiel d of the used modification method with respect to the introduction of carboxylic acid groups are largely improved compared to conventional gasdischargetechniques. Furthermore, thesurfaces aremore stable than surfaces modified with other gas-discharge techniques. No changes in the wettability are observed when the modified polymeric samples are stored at room temperature for at least 12 weeks.

Acknowledgment. This study was financed by Cordis Europa N.V., Roden, The Netherlands.

\section{Appendix: Calculation of the Immobilization Efficiency of C11(:) on PE}

When PE samples are treated with an argon plasma, the polymeric surface is oxidized. Part of the oxygen that is introduced at the surface is present in carboxylic acid groups. These carboxylic acid groups can be derivatized

(48) Delden, van C. J .; Lens, J . P.; Kooyman, R. P. H.; Engbers, G. H. M.; Feijen, J . Biomaterials 1997, 18, 845.

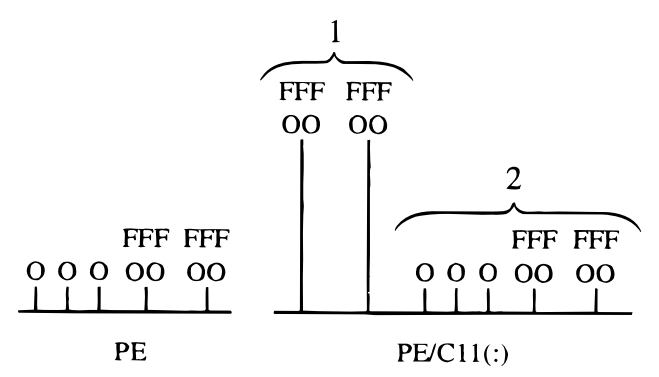

Figure 10. Schematic representation of plasma-treated, washed, and TFE-derivatized PE and PE/C11(:) samples. On thePE/C11(:) samples, oxygen and fluorine originate from the immobilized and derivatized C11(:) molecules (1) and from the oxygen-containing functional groups including carboxylic acid groups introduced by the oxidation during plasma treatment (2).

with TFE (Figure 10). When PE/C11(:) samples are treated with an argon plasma, part of thecoated surfactant layer is immobilized. Simultaneously, the surface is oxidized. Carboxylic acid groups of both sources are derivatized with TFE (Figure 10).

The atomic percentages of oxygen and fluorine at the surfaces of the plasma-treated, washed, and TFE-derivatized PE samples are represented by $\mathrm{O}_{\mathrm{PE}}$ and $\mathrm{F}_{\mathrm{PE}}$, respectively. The atomic percentages of oxygen and fluorine at the surfaces of plasma-treated, washed, and TFE-derivatized PE/C11(:) samples present in the immobilized surfactant molecules are represented by $\mathrm{O}_{\mathrm{PE} / \mathrm{C} 11(\mathrm{)})}^{1}$ and $\mathrm{F}_{\mathrm{PE} / \mathrm{C} 11(\mathrm{)})}^{1}$, respectively. Finally, the atomic percentages of oxygen and fluorinethat are present in the oxidized part of thesurfaces of the plasma-treated, washed, and TFE-derivatized PE/C11(:) samples are represented by $\mathrm{O}_{\mathrm{PE} / \mathrm{C} 11(\mathrm{:})}^{2}$ and $\mathrm{F}_{\mathrm{PE} / \mathrm{C} 11(\mathrm{)})}^{2}$, respectively. The total atomic percentages of oxygen $\left(\mathrm{O}_{\mathrm{PE} / \mathrm{C} 11(\mathrm{)})}\right)$ and fluorine $\left(\mathrm{F}_{\mathrm{PE} / \mathrm{C} 11(\mathrm{l})}\right)$ at the surfaces of the plasma-treated, washed, and TFEderivatized PE/C11(:) samples are given by

$$
\begin{aligned}
& \mathrm{O}_{\mathrm{PE} / \mathrm{C} 11(:)}=\mathrm{O}_{\mathrm{PE} / \mathrm{C} 11(:)}^{1}+\mathrm{O}_{\mathrm{PE} / \mathrm{C} 11(:)}^{2} \\
& \mathrm{~F}_{\mathrm{PE} / \mathrm{C} 11(:)}=\mathrm{F}_{\mathrm{PE} / \mathrm{C} 11(:)}^{1}+\mathrm{F}_{\mathrm{PE} / \mathrm{C} 11(:)}^{2}
\end{aligned}
$$

The immobilization efficiency of C11(:) on PE is defined as the atomic percentage of oxygen present in the carboxylicacid groups of immobilized surfactant molecules relative to the atomic percentage of oxygen present in the carboxylate groups on precoated PE/C11(:) samples $\left(\mathrm{O}_{\mathrm{PE} / \mathrm{C} 11(\mathrm{:}) \text {,coated }}\right)$ :

$$
\begin{aligned}
& \text { immobilization efficiency of } \mathrm{C} 11(\mathrm{:}) \text { on PE [\%] }= \\
& \qquad \frac{\mathrm{O}_{\mathrm{PE} / \mathrm{C} 11(\mathrm{:})}^{1}}{\mathrm{O}_{\mathrm{PE} / \mathrm{C} 11(\mathrm{:}), \text { coated }}} 100
\end{aligned}
$$

When it is assumed that TFE quantitatively reacts with only carboxylic acid groups at the polymeric surfaces and that the expansion of the derivatized surfacelayer due to the introduction of the TFE molecules is one-dimensional and perpendicular to the sample surface, the immobilization efficiency of C11(:) on PE can becalculated according

$$
\begin{aligned}
& \text { immobilization efficiency of } \mathrm{C} 11(\text { :) on PE [\%] }= \\
& \qquad \frac{\mathrm{F}_{\mathrm{PE} / \mathrm{C} 11(:)}^{1}}{1.5 \mathrm{O}_{\mathrm{PE} / \mathrm{C} 11(\mathrm{:}) \text {,coated }}} 100
\end{aligned}
$$

F urthermore, it is assumed that the relative amount of carboxylic acid groups at PE and PE/C11(:) surfaces that 
is introduced through oxidation during the argon plasma treatment is the same. Thus

$$
\frac{F_{P E / C 11(:)}^{2}}{O_{P E / C 11(:)}^{2}}=\frac{F_{P E}}{O_{P E}}
$$

Combination of eqs $\mathrm{A} 2$ and $\mathrm{A} 5$ yields

$$
F_{P E / C 11(:)}^{1}=F_{P E / C 11(:)}-\frac{O_{P E / C 11(:)}^{2}}{O_{P E}} F_{P E}
$$

Combination of eqs $\mathrm{A} 1$ and $\mathrm{A} 3$ yields
$\mathrm{O}_{\mathrm{PE} / \mathrm{C} 11(:)}^{2}=\mathrm{O}_{\mathrm{PE} / \mathrm{C} 11(:)}-$

(imm. eff. of C11(:) on PE [\%]) $\mathrm{O}_{\mathrm{PE} / \mathrm{C} 11(\text { :), coated }}$ 100

Finally, the immobilization efficiency of $C 11($ :) on PE can be calculated by combination of eqs A4, A6, and A7:

immobilization efficiency of C11(:) on PE [\%] =

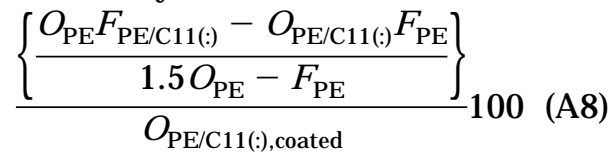

LA970470F 